\title{
Potencial de cobertura do solo e supressão de tiririca (Cyperus rotundus) por resíduos culturais de plantas de cobertura
}

\author{
Lucas da Silva Araújo ${ }^{1}$, Paulo César Ribeiro da Cunha², Pedro Marques da Silveira ${ }^{3 *}$, \\ Maurílio de Sousa Netto ${ }^{4}$, Fernando Castro de Oliveira ${ }^{5}$ \\ http://dx.doi.org/10.1590/0034-737X201562050009
}

\section{RESUMO}

Uma alternativa, em potencial, para a sustentabilidade de sistemas de produção de grãos é o emprego de plantas de cobertura do solo. Pesquisas têm sido realizadas, visando à escolha da espécie para compor o Sistema Plantio Direto em condições do Cerrado brasileiro. Por isso, o objetivo deste experimento foi avaliar o potencial de cobertura do solo pelos resíduos culturais de milheto, guandu-anão e Crotalaria spectabilis e seus efeitos sobre a supressão de tiririca (Cyperus rotundus) em área de Cerrado. O experimento foi conduzido em Latossolo Vermelho distrófico, adotando-se o delineamento experimental em blocos casualizados, com quatro repetições. Os tratamentos foram constituídos por espécies de cobertura do solo: milheto, guandu-anão, C. spectabilis e pousio. Para as culturas de cobertura, foram avaliadas as fitomassas verde e seca e as taxas de decomposição e de cobertura do solo. As culturas foram cortadas noventa dias após emergência e as avaliações das densidades de tiririca no solo foram feitas aos 30, 60, 90 e 120 dias após o corte (DAC). O milheto foi a espécie de cobertura do solo que apresentou a maior produtividade de matéria seca, de $12,71 \mathrm{Mg} \mathrm{ha}^{-1}$. A palhada do guandu-anão apresentou menor velocidade de decomposição. Aos $120 \mathrm{DAC}$, as densidades de tiririca nos tratamentos milheto, guandu-anão e $C$. spectabilis foram de, respectivamente, 56,1, 40,6 e 30,3\%, em comparação com a do pousio.

Palavras-chave: manejo sustentável, plantas daninhas, plantio direto, produção de fitomassa, taxa de decomposição.

\section{ABSTRACT \\ Potential of soil coverage and suppression of purple nutsedge (Cyperus rotundus) by cover crop residues}

Cover crops have great potential for sustainability of crop production systems. Several studies have been conducted to select cover crops for no-tillage systems in the Brazilian Cerrado region. The objective of this experiment was to evaluate the potential for soil cover of millet, dwarf pigeon pea and Crotalaria spectabilis and their effects on the suppression of purple nutsedge (Cyperus rotundus) in the Cerrado region. The experiment was conducted on an Oxisol, in a randomized complete block design with four replications. The treatments consisted of species of cover crops i. e. millet, dwarf pigeon pea and Crotalaria spectabilis and fallow. The dry and green phytomass, phytomass decomposition rate and soil cover rate of the cover crops were evaluated. Cover crops were cut and spread on the soil surface ninety days after emergence. The evaluation of the purple nutsedge density was

\footnotetext{
Submetido em 18/03/2014 e aprovado em 17/07/2015

${ }^{1}$ Instituto Federal Goiano, Urutaí, Goiás, Brasil. lucasilva_31@ @otmail.com

${ }^{2}$ Instituto Federal Goiano, Urutaí, Goiás, Brasil. pcdacunha@ @otmail.com

33 Embrapa Arroz e Feijão, Santo Antônio de Goiás, Goiás, Brasil. pedro.silveira@embrapa.br

${ }^{4}$ Instituto Federal Goiano, Urutaí, Goiás, Brasil. mauriliocaldos@hotmail.com

${ }^{5}$ Instituto Federal Goiano, Urutaí, Goiás, Brasil. castrodeoliveira.10@gmail.com

*Autor para correspondência: pedro.silveira@embrapa.br
} 
carried out at 30, 60, 90 and 120 days after cutting (DAC). Millet showed the highest dry phytomass, $12.71 \mathrm{Mg} \mathrm{ha}^{-}$ 1. Dwarf pigeon pea residue showed lower decomposition rate. The density of purple nutsedge at 120 DAC was $56.1 \%$; $40.6 \%$ and $30.3 \%$ for millet, dwarf pigeon pea and Crotalariaspectabilis compared to fallow.

Key words: biomass production, decomposition rate, no-tillage, sustainable management, weed.

\section{INTRODUÇÃO}

Um dos fatores que contribui para o sucesso do sistema plantio direto (SPD) está ligado à definição de espécies com elevada produtividade de fitomassa para cobertura de solo. Segundo Alvarenga et al. (2001), para a escolha da planta de cobertura são decisivas suas produtividade de fitomassa, disponibilidade de sementes, rusticidade, tolerância ao déficit hídrico, capacidade de extrair nutrientes, possibilidade de utilização comercial e lenta decomposição.

Nas regiões de clima tropical, em razão das condições elevadas de temperatura e umidade, a baixa permanência da palha na superfície do solo é um dos principais obstáculos encontrados para o estabelecimento do SPD. Isso reforça a preocupação de produzir resíduos vegetais adequados para composição do SPD nas condições tropicais. No Cerrado, mesmo quando a palhada é basicamente constituída por gramíneas, a sua decomposição é mais rápida, de forma que a manutenção de uma camada de cobertura de solo, nesse ambiente, torna-se uma atividade complexa, exigindo conhecimento e experiência do produtor (Alvarenga et al., 2001). Além disso, em regiões de inverno seco, a produção e a manutenção de cobertura vegetal do solo para o SPD têm sido os principais desafios da pesquisa agronômica (Soratto \& Crusciol 2008).

Com a adoção do SPD, sem o revolvimento do solo e sem a manutenção da cobertura morta sobre o solo, verifica-se alteração na dinâmica populacional de plantas daninhas. A presença de uma camada de palha sobre a superfície do solo limita a passagem de luz, dificultando a germinação e o crescimento inicial das plântulas. Existem, contudo, os efeitos alelopáticos, oriundos da decomposição da fitomassa ou da exsudação pelas raízes de substâncias químicas que vão exercer efeito inibitório na germinação, ou em algum processo do seu desenvolvimento (Alvarenga et al., 2001).

A tiririca (Cyperus rotundus L.) é uma das mais importantes espécies de plantas daninhas do mundo, por sua rápida reprodução e disseminação, aliada à dificuldade de seu controle. Por isso, inúmeras tentativas de controle químico têm obtido resultados promissores para esta espécie (Durigan et al., 2004). Em termos econô- micos, entretanto, nem sempre é viável. Uma alternativa de controle consiste no emprego do SPD. A fitomassa seca mantida na superfície do solo forma uma barreira física, dificultando o estabelecimento e a disseminação da tiririca. O controle de C. rotundus foi observado por Jakelaitis et al. (2003), que relataram redução da população de tiririca, no plantio direto, em comparação com a do plantio convencional.

Este experimento teve por objetivo avaliar a produtividade de fitomassas verde e seca, a dinâmica de decomposição, o potencial de cobertura do solo dos resíduos culturais de milheto, guandu-anão e $C$. spectabilis e seus efeitos sobre a supressão de tiririca (C.rotundus) em área de Cerrado.

\section{MATERIAL E MÉTODOS}

A pesquisa foi desenvolvida em área localizada na Fazenda Experimental do Instituto Federal de Educação, Ciência e Tecnologia Goiano, IF Goiano - Câmpus Urutaí, Goiás, cujas coordenadas geográficas são $17^{\circ} 28^{\prime} 41^{\prime \prime} \mathrm{S}$, $48^{\circ} 11^{\prime} 35^{\prime \prime} \mathrm{O}$ e altitude de 800 metros. O clima do local foi classificado como do tipo Aw (Köppen), com duas estações bem definidas (seca e chuvosa). Os dados referentes às médias de temperaturas máxima e mínima, umidade relativa do ar e precipitação pluvial durante a condução do experimento encontram-se na Figura 1.

O solo da área experimental foi classificado como Latossolo Vermelho distrófico, com as seguintes características químicas na camada arável de $(0-20 \mathrm{~cm}): \mathrm{pH}$ $\left(\mathrm{CaCl}_{2}\right)=5,1 ; \mathrm{Ca}^{+2}\left(\mathrm{cmol}_{\mathrm{c}} \mathrm{dm}^{-3}\right)=1,9 ; \mathrm{Mg}^{+2}\left(\mathrm{cmol}_{\mathrm{c}} \mathrm{dm}^{-3}\right)=$ 0,$8 ; \mathrm{Al}^{+3}\left(\mathrm{cmol}_{\mathrm{c}} \mathrm{dm}^{-3}\right)=0,1 ; \mathrm{K}^{+}\left(\mathrm{cmol}_{\mathrm{c}} \mathrm{dm}^{-3}\right)=0,28 ; \mathrm{P}(\mathrm{mg}$ $\left.\mathrm{dm}^{-3}\right)=3,4 ; \mathrm{V}(\%)=53 ;$ M.O. $=25 \mathrm{~g} \mathrm{dm}^{-3}$.

Antes da instalação do experimento foi feito o manejo em pré-semeadura das plantas daninhas, entre as quais predominava infestação de tiririca, com $185 \pm 19$ plantas $\mathrm{m}^{-2}$; para isso utilizou-se o herbicida glyphosate, na dosagem de $1,92 \mathrm{~kg} \mathrm{ha}^{-1}$ i.a. aplicado via pulverizador costal. Uma semana após a dessecação fez-se a sulcagem, com espaçamento de $0,50 \mathrm{~m}$ entre as linhas de plantio. Imediatamente após a abertura dos sulcos, foi realizada a semeadura das plantas de cobertura. Assim como nos trabalhos de Teixeira et al. (2010) e Suzuki \& Alves (2006), as culturas de cobertura não foram adubadas. 
Foram avaliadas três espécies de culturas de cobertura: Pennisetum glaucum (milheto ADR 500, utilizando-se $20 \mathrm{~kg} \mathrm{ha}^{-1}$ de sementes no plantio), Cajanus cajan (guandu-anão cultivar Super N, com 12 sementes por metro) e Crotalaria spectabilis (16 sementes por metro), mais o pousio (vegetação espontânea). A semeadura manual das espécies de cobertura foi realizada em 02 de janeiro de 2013, em delineamento experimental de blocos ao acaso, com quatro repetições, perfazendo 16 parcelas. As dimensões das parcelas foram de 16,0 m x 3,0 m. Para avaliação das variáveis fitotécnicas relacionadas com as culturas de cobertura, utilizaram-se as duas linhas centrais de cada parcela, constituindo área útil de $8 \mathrm{~m}^{2}$. O corte das três espécies de plantas de coberturas e das plantas do pousio foi realizado simultaneamente, em 11 de abril de 2013.

Para a avaliação da fitomassa, foram coletadas as partes aéreas das espécies vegetais, aos 90 dias após a emergência das culturas. Nessa época, foram determinadas as quantidades de matérias verde e seca produzidas; para isso foram feitas amostragens em dois pontos ao longo das parcelas. Foram cortadas rente ao solo duas linhas de um metro, em que foi medida a fitomassa de todo o material vegetal. $\mathrm{O}$ material verde foi pesado e posteriormente colocado em estufa de circulação forçada de ar, a $70{ }^{\circ} \mathrm{C}$, até estabilização da fitomassa, determinando-se a quantidade de fitomassa seca e transformandose os valores para quilos por hectare. Após a coleta da fitomassa, as plantas de cobertura foram roçadas de tal maneira que o material remanescente na superfície do solo ficasse em fragmentos em torno de $4 \mathrm{~cm}$, espalhados homogeneamente por toda a área da parcela.

A decomposição da palhada foi determinada conforme Teixeira et al. (2010), utilizando-se o método das 'litter bags', com malha de $1 \mathrm{~mm}$, colocadas na superfície, em contato direto com o solo. As dimensões das bolsas foram de $0,2 \times 0,2 \mathrm{~m}$, perfazendo $0,04 \mathrm{~m}^{2}$. A quantidade de palhada utilizada para preenchimento das bol-

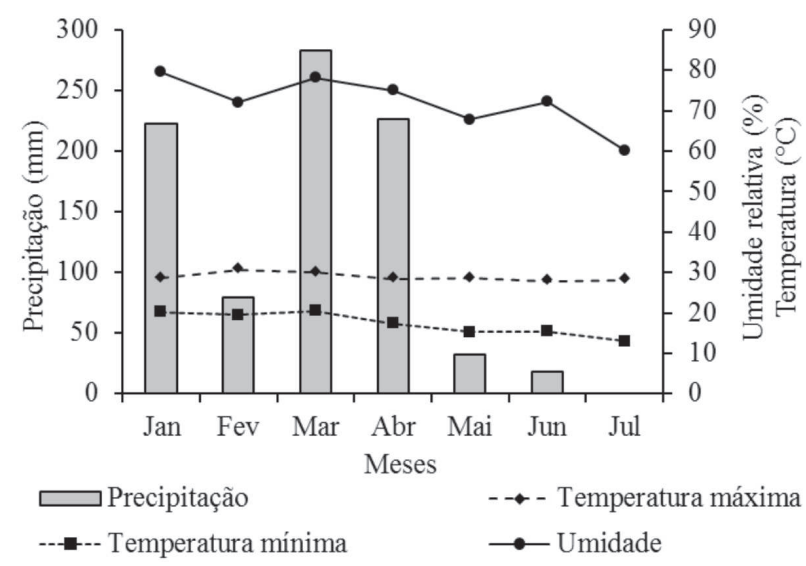

Figura 1: Precipitação pluvial, temperaturas máxima e mínima e umidade relativa do ar no ano de 2013 na área experimental. sas foi proporcional à produtividade de fitomassa seca de cada cultura de cobertura. Para o preenchimento das bolsas, as plantas passaram por pré-secagem ao ar, completada em estufa de circulação forçada. As bolsas foram distribuídas ao longo da área central das parcelas em contato direto com a superfície do solo. Foram realizadas oito coletas (uma bolsa por coleta), aos 15, 30, 45, 60, 75, 90, 105 e 120 dias após o corte das culturas.

A cobertura vegetal foi estimada, utilizando-se um quadrado de ferro de 0,5 m de lado, tendo uma linha de náilon disposta em diagonal, com 13 pontos espaçados de $0,05 \mathrm{~m}$. As medições consistiram na contagem das interceptações da palha nos referidos pontos, calculando-se assim o percentual de cobertura vegetal.

A eficiência dos tratamentos na supressão da população da tiririca foi avaliada aos 30, 60, 90 e 120 dias após o corte (DAC) das culturas de cobertura, por meio de duas amostragens ao acaso na parcela, com o uso de um quadrado de $0,25 \mathrm{~m}^{2}$, recolhendo-se e contando-se todas as plantas presentes. O material coletado foi encaminhado ao Laboratório de Fitotecnia e, posteriormente, secado em estufa, por 72 horas, a $65{ }^{\circ} \mathrm{C}$, para determinação da fitomassa seca.

Os dados foram submetidos à análise de variância, aplicando-se o teste $\mathrm{F}$ para significância e as médias comparadas pelo teste de Tukey, a 5\% de probabilidade. As análises de regressão relativas à decomposição foram realizadas com o software ASSISTAT 7.7 Beta (Silva \& Azevedo, 2002).

\section{RESULTADOS E DISCUSSÃO}

As plantas de cobertura apresentaram diferenças quanto às produtividades de fitomassas verde e seca, após 90 dias da emergência (Tabela 1). O milheto foi a espécie que apresentou maior produtividade de fitomassa verde, valor superior às alcançadas pelas leguminosas guandu-anão e $C$. spectabilis.

As produtividades de fitomassa verde do milheto e o guandu-anão foram superiores às dos outros estudos. Sodré Filho et al. (2004) relataram produtividade de fitomassa verde, para milheto e guandu-anão, de 7,18 e $5,03 \mathrm{Mg} \mathrm{ha}^{-1}$, respectivamente, quando cultivados em sistema plantio direto, na região de Planaltina, DF.

Em relação à produção de matéria seca, o milheto apresentou maior produtividade, seguido por guandu-anão e C. spectabilis. Segundo Alvarenga et al. (2001), a quantidade mínima de resíduos requeridas para uma eficiente cobertura do solo é em torno de $6 \mathrm{Mg} \mathrm{ha}^{-1}$ de fitomassa seca, valor não alcançado pela espécie Crotalaria spectabilis.

Maiores produtividades destas plantas de cobertura foram encontrados por Carneiro et al. (2008) com valo- 
Tabela 1: Produtividade de fitomassas verde e seca das plantas de cobertura milheto, guandu-anão e Crotalaria spectabilis, avaliadas aos 90 dias após a emergência

\begin{tabular}{|c|c|c|}
\hline \multirow{2}{*}{ Plantas de cobertura } & \multicolumn{2}{|c|}{ Fitomassa $\left(\mathrm{Mg} \mathrm{ha}^{-1}\right)$} \\
\hline & Verde $^{1}$ & Seca $^{1}$ \\
\hline Milheto & $37,97 \mathrm{a}$ & $12,71 \mathrm{a}$ \\
\hline Guandu-anão & $24,85 b$ & $7,66 b$ \\
\hline Crotalaria spectabilis & $21,31 \mathrm{~b}$ & $3,96 b$ \\
\hline Teste F & $9,28^{*}$ & $20,22^{* *}$ \\
\hline $\mathrm{CV}(\%)$ & 20,54 & 24,07 \\
\hline DMS & 12,50 & 4,23 \\
\hline
\end{tabular}

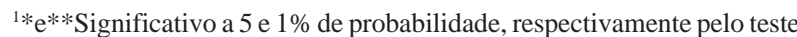
F. ${ }^{1}$ Médias, seguidas de letras distintas na vertical, diferem significativamente entre si a 5\% de probabilidade pelo teste de Tukey.

res de 16,39, 16,93 e 9,13 $\mathrm{Mg} \mathrm{ha}^{-1}$, respectivamente, para o milheto, guandu-anão e $C$. spectabilis, na região de Jataí, GO, em Latossolo Vermelho distroférrico. De acordo com os autores, provavelmente a época de semeadura e a adubação utilizada proporcionaram condições adequadas para o desenvolvimento das espécies, pois, na região, constataram-se elevados índices de precipitação pluvial no início do desenvolvimento vegetativo das culturas.

Na avaliação da decomposição da palhada, a equação ajustada à perda de fitomassa da palhada de milheto (Figura 2A) mostrou perda relativa de 70,2\%, aos 120 dias após corte (DAC), enquanto, para o guandu-anão (Figura 2B), aos 120 DAC, constatou-se perda da fitomassa seca da palhada de 60,29\%. Para a C. spectabilis (Figura 2C), a perda relativa da palhada foi de 79,07\%. Assim sendo, observou-se que os resíduos culturais de guandu-anão persistiram mais no solo que os do milheto e da $C$. spectabilis.

A diferença na taxa de decomposição dos resíduos pode estar relacionada com a composição química do material vegetal utilizado. Santos et al. (2009) relataram que quanto maiores a relação $\mathrm{C} / \mathrm{N}$, o teor de celulose, de hemicelulose, de lignina e polifenóis mais lenta é a decomposição da fitomassa. Entretanto, o milheto, mesmo sendo uma gramínea, sua palhada persistiu menos que a do guandu-anão, fato não observado no trabalho de Pelá et al. (1999). De acordo com esses autores, o milheto foi o material mais resistente, apresentando a percentagem de perda, ao longo de 73 dias, de 44,4\%, seguido do guandu-anão, com 49,4\%. Também Kliemann et al. (2006) observaram, aos $150 \mathrm{DAC}$, perda relativa da fitomassa da palhada do milheto de $58 \%$, menor que a do guandu de $65 \%$.

$\mathrm{Na}$ análise da taxa de cobertura do solo pelos resíduos culturais das espécies, no decorrer do tempo, verificouse efeito polinomial negativo para as plantas de cobertura guandu-anão, milheto e C. spectabilis e para o pousio (Fi- gura 3). De acordo com as equações de regressão, as palhadas de guandu-anão e C. spectabilis proporcionaram melhor cobertura inicial do solo, diferentemente das coberturas formadas pelo milheto e o pousio.

Aos 30 DAC da fitomassa, as palhadas de guandu-anão (Figura 3A) e C. spectabilis (Figura 3C) apresentaram taxa
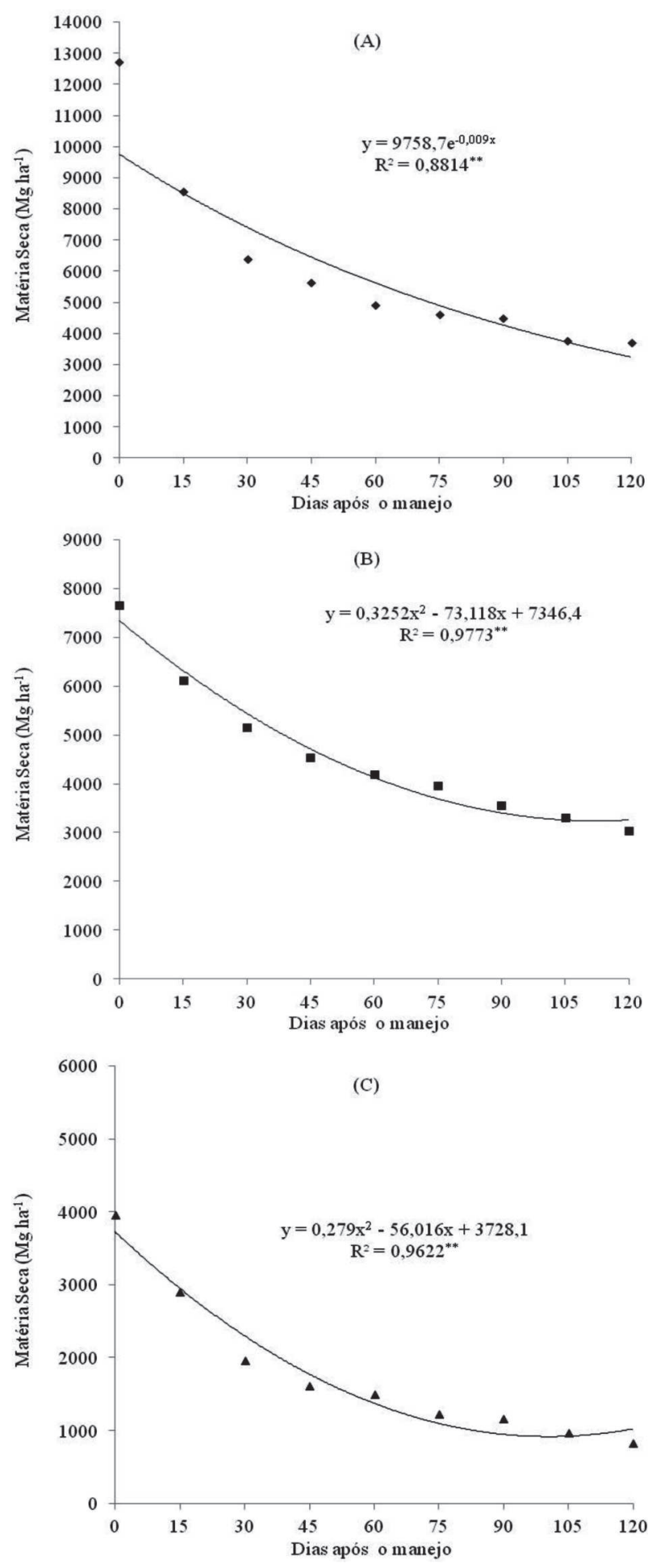

Figura 2: Decomposição das palhadas de milheto (A), guanduanão (B) e Crotalaria spectabilis (C) sobre o solo, em função do tempo após o corte das culturas. 
de cobertura superior a $70 \%$, diferentemente da cobertura vegetal formada pelo milheto (Figura 3B) e pelo pousio (Figura 3D), que proporcionaram taxas de, respectivamente, 59,6 e 54,78\%. A baixa taxa de cobertura do solo proporcionada pelo milheto provavelmente ocorreu pela decomposição inicial mais rápida de seus resíduos, por causa do potencial de acumulação de nitrogênio pela espécie (Braz et al., 2004). Nascente \& Crusciol (2013) relataram alta taxa de decomposição do milheto, justificada pelo elevado teor de nitrogênio no limbo foliar. Teores de nitrogênio no limbo foliar do milheto maiores que $3 \%$ foram observados por Braz et al. (2004).

Após 120 DAC, os resíduos de todas as culturas de coberturas do solo apresentaram baixa taxa de cobertura, com valores inferiores a 50\%. Segundo Alvarenga et al. (2001), no sistema plantio direto, deve-se ter pelo menos $50 \%$ da superfície do solo coberta com resíduos e estes devem ter uma taxa de decomposição compatível com a manutenção de cobertura deixada pelas culturas antecessoras. Contudo, neste experimento, os resíduos culturais das espécies de cobertura foram eficientes em cobrir $50 \%$ da superfície do solo até os 60 DAC; após esse período, houve perda considerável de fitomassa da matéria seca, que, consequentemente. proporcionou baixa cobertura do solo.

Na Tabela 2, são apresentadas a densidade e a fitomassa seca da tiririca, em razão dos resíduos das plan-

(A)

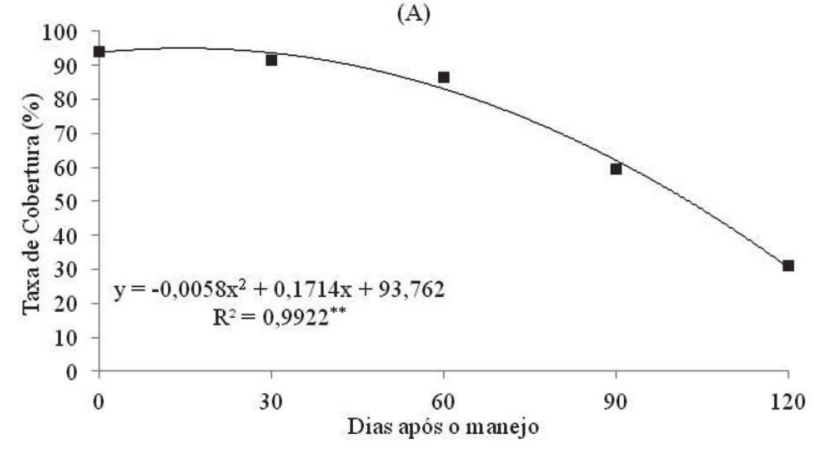

(C)

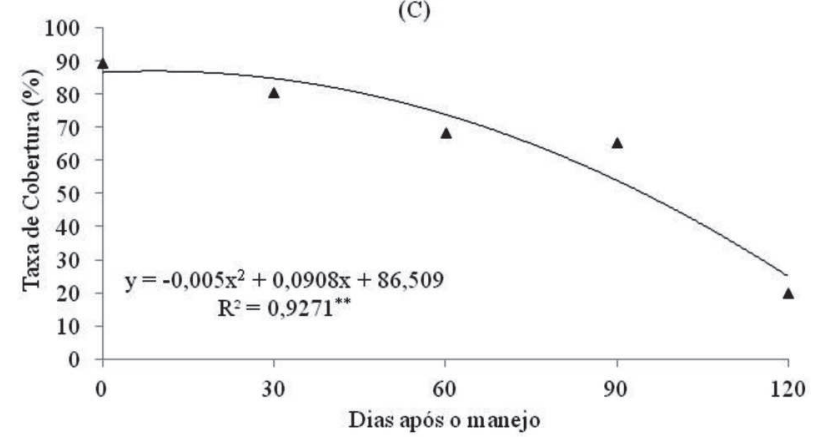

tas de cobertura, as quais diferiram significativamente das do pousio. Observou-se redução significativa do número de indivíduos e da fitomassa seca aos 120 DAC, na presença de resíduos culturais de C. spectabilis, porém sem diferença significativa em relação ao milheto e guandu-anão. Nessa ocasião, as densidades de tiririca nos tratamentos milheto, guandu-anão e $C$. spectabilis foram de, respectivamente, 56,1, 40,6 e 30,3\% em comparação com a do pousio.

A maior ocorrência de tiririca foi verificada na área de pousio, em que a cobertura morta era formada pelas espécies daninhas: trapoeraba (Commelina benghalensis), poaia branca (Richardia brasiliensis), tiririca (Cyperus rotundus), apaga fogo (Alternanthera tenella), timbete (Cenchrus echinatus), erva-de-touro (Tridax procumbens) e falsa serralha (Emilia sanchifolia). Essas espécies interferiram pouco na dinâmica populacional da tiririca e demonstraram baixo potencial de supressão ao estabelecimento e propagação desta espécie.

De modo geral, houve baixa eficiência da planta de cobertura milheto para a supressão da população de tiririca, evidenciando que a sua elevada quantidade de palhada influenciou pouco no comportamento desta espécie altamente competitiva. Estes resultados mostram que a qualidade dos resíduos culturais é um fator fundamental para a expressão do potencial de supressão de plantas daninhas pelas culturas de cobertura.

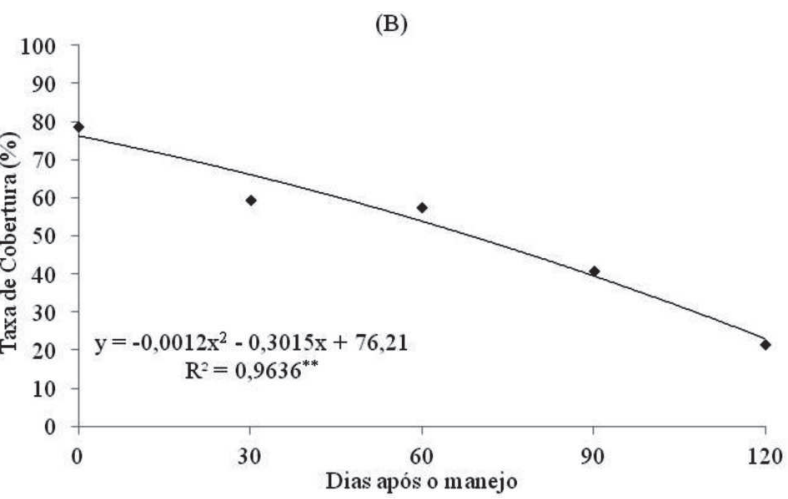

(D)

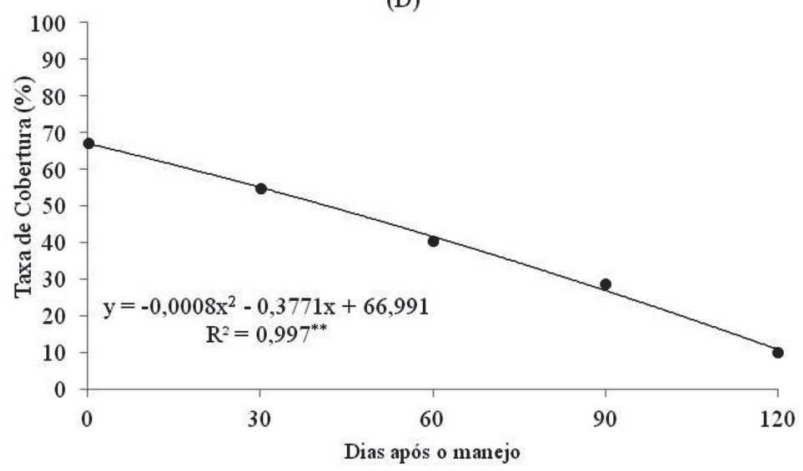

Figura 3: Taxa de cobertura do solo pelas palhadas de guandu-anão (A), milheto (B) Crotalaria spectabilis (C) e pousio (D), em função do tempo após o corte das culturas. 
Tabela 2: Densidade e fitomassa seca da tiririca (Cyperus rotundus) avaliadas aos 30, 60, 90 e 120 dias após o corte das culturas de cobertura do solo

\begin{tabular}{|c|c|c|c|c|c|c|c|c|}
\hline \multirow{3}{*}{$\begin{array}{l}\text { Planta } \\
\text { de cobertura }\end{array}$} & \multicolumn{4}{|c|}{ Densidade $\left(\mathrm{n}^{0} \mathrm{~m}^{-2}\right)$} & \multicolumn{4}{|c|}{ Fitomassa seca $\left(\mathrm{g} \mathrm{m}^{-2}\right)$} \\
\hline & \multicolumn{8}{|c|}{ Dias após o corte } \\
\hline & 30 & 60 & 90 & 120 & 30 & 60 & 90 & 120 \\
\hline Milheto & 45,1 & 69,1 & $65,0 \mathrm{ab}$ & $86,5 b$ & 1,22 & 2,80 & 3,40 & $3,90 \mathrm{~b}$ \\
\hline Guandu-anão & 40,7 & 48,6 & $52,7 \mathrm{~b}$ & $62,6 b$ & 1,60 & 2,50 & 3,40 & $3,00 \mathrm{~b}$ \\
\hline C. spectabilis & 24,7 & 38,5 & $43,0 \mathrm{~b}$ & $46,7 b$ & 0,50 & 1,50 & 1,80 & $1,80 \mathrm{~b}$ \\
\hline Pousio & 105,2 & 76,1 & $120,3 a$ & $154,1 \mathrm{a}$ & 5,70 & 5,60 & 9,90 & $11,20 \mathrm{a}$ \\
\hline Teste F & $2,8^{\text {ns }}$ & $1,00^{\mathrm{ns}}$ & $6,6^{*}$ & $14,3^{* *}$ & $2,8^{\text {ns }}$ & $1,00^{\text {ns }}$ & $2,3^{\text {ns }}$ & $6,9^{*}$ \\
\hline $\mathrm{CV}(\%)$ & 18,93 & 14,12 & 11,20 & 9,23 & 18,24 & 12,85 & 11,16 & 10,64 \\
\hline DMS & 92,5 & 75,5 & 59,3 & 55,3 & 6,18 & 7,60 & 10,3 & 7,1 \\
\hline
\end{tabular}

*** Significativo a 5 e $1 \%$ de probabilidade, respectivamente pelo teste $\mathrm{F}$. ${ }^{\text {ns }}$ Não significativo.

Médias, seguidas de letras distintas na vertical, diferem significativamente entre si a 5\% de probabilidade pelo teste de Tukey.

\section{CONCLUSÕES}

O milheto foi a espécie de cobertura do solo que apresentou a maior produtividade de fitomassa.

A palhada do guandu-anão apresentou menor velocidade de decomposição.

A cobertura morta proporcionada pelos resíduos culturais de Crotalaria spectabilis mostrou interferência na dinâmica populacional da tiririca, condicionando reduções no número de indivíduos e na fitomassa seca desta planta daninha.

\section{AGRADECIMENTOS}

Os autores agradecem ao Instituto Federal GoianoCâmpus Urutaí, pela concessão da bolsa de iniciação científica ao primeiro autor.

\section{REFERÊNCIAS}

Alvarenga RC, Lara Cabezas WA, Cruz JC \& Santana DP (2001) Plantas de cobertura de solo para sistema plantio direto. Informe Agropecuário, 22:25-36.

Braz AJBP, Silveira PM, Kliemann HJ \& Zimmermann FJP(2004) Acumulação de nutrientes em folhas de milheto e dos capins braquiária e mombaça. Pesquisa Agropecuária Tropical, 34:83-87.

Carneiro MAC, Cordeiro MAS, Assis PCR, Moraes ES, Pereira HS, Paulino HB \& Souza E (2008) Produção de fitomassa de diferentes espécies de cobertura e suas alterações na atividade microbiana de solo de Cerrado. Bragantia, 67:455-462.

Durigan JC, Timossi PC \& Leite GL (2004) Controle químico da tiririca (Cyperus rotundus), com e sem cobertura do solo pela palha de cana-de-açúcar. Planta Daninha, 22:127-135.

Jakelaitis A, Ferreira LR, Silva AA, Agnes EL, Miranda GV \& Machado AFL (2003) Efeitos de sistemas de manejo sobre a população de tiririca. Planta Daninha, 21:89-95.

Kliemann HJ, Braz AJPB \& Silveira PM (2006) Taxas de decomposição de resíduos de espécies de cobertura em latossolo vermelho distroférrico. Pesquisa Agropecuária Tropical, 36:21-28.
Nascente AS \& Crusciol CAC (2013) Cover crops affeting levels of ammonium and nitrate in the soil and upland rice development. Semina: Ciências Agrárias, 34:2189-2202.

Pelá A, Silva MS, Costa LA, Silva CJ, Zucareli C, Drecarli CL \& Matter UF (1999) Avaliação da resistência à decomposição de dez espécies de plantas de cobertura visando o plantio direto. Revista Plantio Direto, 53:26-33.

Santos R, Siqueira R, Lima C, Almeida A, Pedrosa A \& Oliveira C (2009) Decomposição e liberação de nitrogênio de duas espécies de adubos verdes manejados no período seco em cafezal. Revista Brasileira de Agroecologia, 4:1342-1345.

Silva F \& Azevedo CAV (2002) Versão do programa computacional Assistat para o sistema operacional Windows. Revista Brasileira de Produtos Agroindustriais, 4:71-78.

Sodré Filho J, Cardoso NA, Carmona R \& Carvalho AM (2004) Fitomassa e cobertura do solo de culturas de sucessão ao milho na Região do Cerrado. Pesquisa Agropecuária Brasileira, 39:327-334.

Soratto OS \& Crusiol CAC (2008) Produção de fitomassa e acúmulo de nutrientes pela aveia-preta em função da aplicação de calcário e gesso em superfície na implantação do sistema plantio direto. Ciência Rural, 38:928-935.

Suzuki LEAS \& Alves MC (2006) Fitomassa de plantas de cobertura em diferentes sucessões de culturas e sistemas de cultivo. Bragantia, 65:121-127.

Teixeira CM, Carvalho JG, Silva CA, Andrade MJB \& Pereira JM (2010) Liberação de macronutrientes das palhadas de milheto solteiro e consorciado com feijão-de-porco sob cultivo de feijão. Revista Brasileira de Ciência do Solo, 34:497-505.

Rev. Ceres, Viçosa, v. 62, n.5, p. 483-488, set-out, 2015 